\title{
Life Cycle of Cydalima perspectalis (Walker) (Lepidoptera: Crambidae) in Craiova Area
}

\author{
Raluca STAN*, Ion MITREA \\ Faculty of Horticulture, University of Craiova, Romania \\ *corresponding author: ralucaral.946@yahoo.com \\ BulletinUASVM Horticulture 77(2) / 2020 \\ Print ISSN 1843-5254, Electronic ISSN 1843-5394 \\ DOI:10.15835/buasvmcn-hort: 2020.0035
}

\begin{abstract}
Buxus sempervirens Linné is one of the most cultivated ornamental species, but in recent years it has faced a dangerous pest, Cydalima perspectalis (Walker) (Lepidoptera: Crambidae) native to the Asian Continent (China, Japan, Korea). In 2019 we conducted some investigations on the life cycle of this pest. The research was carried out both in the laboratory and in the field, in the 'Al. Buia' Botanical Garden from Craiova. Under laboratory conditions, this species has developed four complete generations, and the fifth generation, partial. The temperature in the laboratory was between $23.5^{\circ} \mathrm{C}-26^{\circ} \mathrm{C}$, and the photoperiod during the study was between $12-15$ hours of light and 12-9 hours of darkness. In the field this pest has developed three complete generations and the fourth was partial. The number of days for the generations developed in the laboratory is 272 days, and for the field population 286 days.
\end{abstract}

Keywords: Buxus spp., Cydalima perspectalis, evolutionary cycle

\section{Introduction}

The Box Tree Moth - Cydalima perspectalis (Walker) (Lepidoptera: Crambidae) is originating from the Asian Continent (China, Japan, Korea) (Inoue, 1982; Park, 2008). On the European Continent this pest was first detected in 2007 in Germany (Billen, 2007), it is considered that the species was introduced to the area in 2005 or even earlier. Van der Straten and Muus (2010), note that the first reports of larval attack are from Kehl as a possible infestation in 2006 and safe reports of the species in 2007 from Kehl and Weil-am-Rhein to near Basel, spreading further in the country.

In 2008 the species managed to spread to Netherland, France, Switzerland, Austria and the United Kingdom, and in the following years managed to colonize more than half of the countries on the European Continent (Bella, 2013; Feld trauer et al., 2009; Hizal et al., 2012; Korycinska and Eyre, 2009; Leuthardt et al., 2010; Matošević, 2013; Mitchell, 2009; Muus et al., 2009; Ostojić et al., 2015; Sáfián and Horváth, 2011; Salisbury et al., 2012; Seljak, 2012). In Romania, this pest was first reported in 2010, in three different locations from Bucharest (Iamandei, 2010), but also in 2011 being present in the northwestern part of Bucharest and in the yard of a kindergarten (Szekely et al., 2011), in Timisoara the first larvae were observed in 2013 in a park (Fora and Poșta, 2015), in other localities in Timiș county (Gugea and Vîrteiu, 2017), in Constanța (Skolka and Zaharia, 2014), in Cluj (Bunescu and Florian, 2016; Oltean et. al., 2017), in Arad county (Don et. al., 2016), in Satu Mare (Katona et. al., 2016), in Sălaj (Katona et. al., 2016), and in Craiova was reported in 2018 (Mitrea and Stan, 2018).

Since its arrival in Europe, the taxonomy of this pest has been repeatedly disturbed, being 
associated with several genera: Palpita, Diaphania, Glyphodes, Neoglyphodes, Phakellura (Kawazu etal., 2007, Korycinska and Eyre, 2009; Maruyama and Shinkaji, 1987, 1991, 1993; Szekely et al., 2011), but Mally and Nuss, (2010), clarified the situation in a paper on the phylogeny and nomenclature of this species by classifying it as Cydalima.

Symptoms of infestation include damage caused by larvae feeding with leaves, which can leave only the skeleton of the foliage (Leuthardt and Baur, 2013). The larvae can completely defoliate the host plant and eventually lead to its death.

Cydalima perspectalis Walker, is a monophagous species, (Van der Straten and Muus, 2010; Leuthardt and Baur, 2013; Wan et al., 2014), but in Asia it has been reported on other species such as: Buxus sinica Rehder \& E.H. Wilson, Buxus microphylla Siebold \& Zucc., Buxus microphylla var. insularis Siebold \& Zucc., Buxus microphylla var. Japonica Siebold \& Zucc., Buxus rugulosa Hatusima, Ilex purpurea Hassk., Euonymus japonicas Thunberg, Euonymus alatus (Thunb.) Siebold, Murraya paniculata (L.) Jack. (Wan et al., 2014; Wang, 2008).

In Europe, the larvae feed on several species of Buxus: Buxus microphylla, Buxus sempervirens, Buxus sinica and Buxus sinica var cultivars Insularis and Buxus sempervirens Rotundifolia (Mally and Nuss, 2010; Korycinska and Eyre, 2009; Leuthardt et al., 2010; Székely et al., 2011; Hizal, 2012). The number of generations of this lepidoptera changes depending on the climatic conditions of the region (Maruyama and Shinkaji, 1987; Wan et al., 2014). In Asia, 3-5 annual generations appear (She and Feng, 2006, Wan et al., 2014) (in Japan, three generations from May to September), in Central Europe, Nacambo et al. (2014) reported only two generations per year. In northeastern Italy, Santi et al., (2015), found that $C$. perspectalis completes three generations per year. On the European Continent this species develops 2-3 generations, and in some areas with a warmer climate it can develop even a fourth generation (Leuthardt et al., 2010; Brua, 2013, 2014). In Romania in Cluj, Cydalima perspectalis Walker develops two complete generations, and the third generation is partial (Oltean et al., 2017).

For the developmental stages of egg, larvae and pupae, the temperatures varies between $8-12^{\circ} \mathrm{C}$, depending on the environmental factors as well as the geographical position of the researched population (Maruyama and Shinkaji, 1987; Nacombo et al., 2014). To determine the larval stages, Maruyama and Shinkaji (1991), performed measurements of the cephalic capsules of the larvae, thus determining 7 larval instars. The average values for the development period of hibernating larvae are 44.6 days at a constant temperature of $15^{\circ} \mathrm{C}, 25.8$ days at $20^{\circ} \mathrm{C}, 15.7$ days at a temperature of $25^{\circ} \mathrm{C}$ and 15.0 days at $30^{\circ} \mathrm{C}$. Complete larval development lasts between 17-87 days, depending on temperature (Maruyama and Shinkaji, 1987). Maruyama and Shinkaji (1991) reported that in the laboratory at $25^{\circ} \mathrm{C}$ the larvae of $C$. perspectalis developed 6 instars, instars 1-5 developed in 3 days and the 6th stage developed in 8 days. In areas of origin, full development for the second and third generation of the same year occurs in $24.9 \pm 2.89$ days at a temperature of $25^{\circ} \mathrm{C}$ (Maruyama and Shinkaji, 1987), and in North China the second and third generations of the same year completed their development within $24.9 \pm 0.73$ days at a temperature of $27^{\circ} \mathrm{C}$ (Zhang et al., 2007). The mean period for the pupae stage is $38.4 \pm 1.49$ days at a constant temperature of $15^{\circ} \mathrm{C}, 17.3 \pm 0.78$ days at $20^{\circ} \mathrm{C}, 10.0 \pm 0.36$ days at $25^{\circ} \mathrm{C}$ and $7.1 \pm 0.43$ days at $30^{\circ} \mathrm{C}$ (Maruyama and Shinkaji, 1987).

Adult mating occurs only once in their lifetime and lasts about 2 hours (Cheng, 2005). The mean values for the preoviposition period were 5.5 days at $15^{\circ} \mathrm{C}$ and 3.2 days at $20^{\circ} \mathrm{C}, 2.3$ days at $25^{\circ} \mathrm{C}$ and 2.2 days at $30^{\circ} \mathrm{C}$ (Maruyama and Shinkaji, 1987). Female fertility depends on the generation, decreasing from the hibernating generation to the third generation, from about 500 to 200 eggs (Wan et al., 2014). The eggs are laid on the underside of the leaves of the host plant, in groups of about 20-30 eggs (Bella, 2013). The lifespan of females is $8.02 \pm 0.18$ days and $8.69 \pm 0.12$ days for males (Zhou et al., 2005).

Studies conducted in Japan have reported a different duration of development of Cydalima eggs at different temperatures, so it has been shown that with increasing temperature, development (in days) decreases. At a temperature of $15^{\circ} \mathrm{C}$ the egg development period lasts $15.3 \pm 0.64$ days, at $20^{\circ} \mathrm{C}$ it lasts $7.1 \pm 0.23$ days, at $25^{\circ} \mathrm{C}$ it lasts $4.0 \pm 0.15$ days, at $30^{\circ} \mathrm{C}$ it lasts $3.0 \pm 0.10$ days (Maruyama and Shinkaji, 1987). Diapause is induced by a length of day less than $13.5 \mathrm{~h}$ (Maruyama and Shinkaji, 
1993; Xiao et al., 2011), so the life cycle of the Box Tree Moth includes a diapause of 6-8 weeks at low temperatures (Nacombo et al., 2014).

In China most larvae overwinter in the $3^{\text {rd }}$ or $4^{\text {th }}$ instar (She and Feng, 2006, Xiao et. al., 2011), and in Japan they enter to diapause in the $4^{\text {th }}$ or $5^{\text {th }}$ instar (Maruyama and Shinkaji, 1991). In Europe this species overwinter in the third larval stage (Nacombo et al., 2014). In the spring, the feeding activity restarts.

\section{Materials and methods}

In 2019 we performed some investigation regarding the life cycle of Cydalima perspectalis Walker. The researches were conducted both in the laboratory and in the field in the 'Al. Buia' Botanical Garden from Craiova. For the research carried out in the laboratory, the biological material was collected from the field in February, before the beginning of the pest activity and taken to the Entomology Laboratory of the Faculty of Horticulture and placed in breeding cages (Fig.1). In the laboratory we monitored the average temperature and the photoperiod to which the larvae were exposed, and in the field we monitored the average temperature and precipitations. During the research, the following aspects were noted: the beginning of the hibernating larvae activity, the succession of developmental stages and number of generations per year.

\section{Results and discussions}

The experimental results obtained in 2019 following the research conducted in the laboratory of the Faculty of Horticulture and the 'Al. Buia' Botanical Garden regarding the succession of generations of The Box Tree Moth are presented in Table 1.

In laboratory conditions the overwinter generation started its activity on March 4 , and in the field on the March 8. The feeding period of the hibernating larvae until the appearance of the first pupae was 24 days at an average temperature of $23^{\circ} \mathrm{C}$, in the field the development of the larvae was prolonged for a period of 41 days, due to low temperature and precipitation during this period $\left(11.0^{\circ} \mathrm{C}\right.$ average monthly temperature and 24.0 $\mathrm{mm}$ average rainfall in March and $11.9^{\circ} \mathrm{C}$ average monthly temperature and $42.0 \mathrm{~mm}$ average rainfall in April) (Fig. 2). In the laboratory the first pupae were observed on March 28, the pupation period lasted 10 days, and the first adult appeared on April 7 (Fig. 3), after 3 days the eggs were laid.

In field the first pupae were observed on April 18 , the period of the pupation was 15 days. And the first adults were observed on May 3. The minimum development period of the hibernating generation in the laboratory was 34 days and in the field was 56 days. The preoviposition period was 3 days in the laboratory, and the incubation period was 6 days, the larvae of the first generation started their feeding activity on April 16, their evolution period

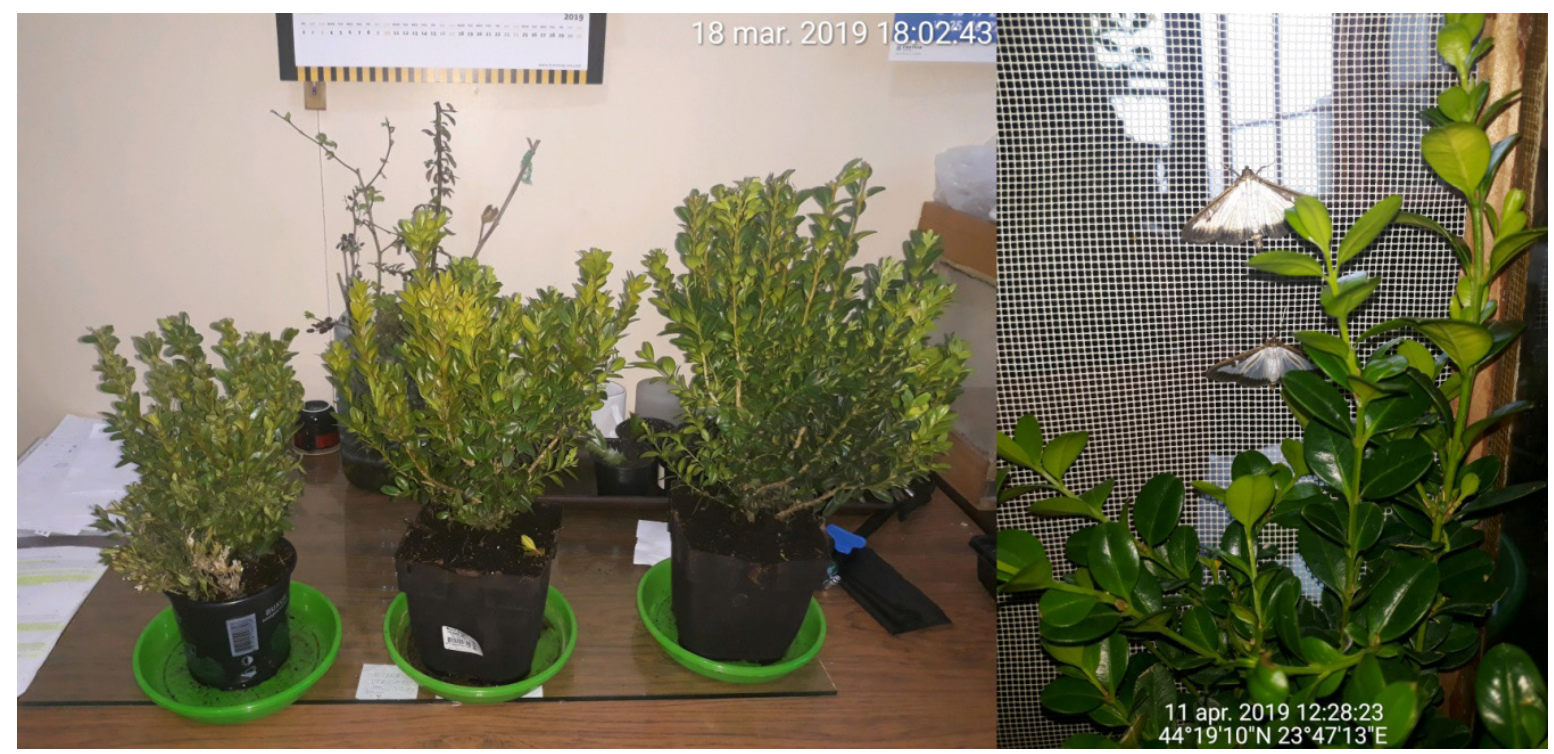

Figure 1. Buxus sempervirens Linné, bushes (left) and C. perspectalis adults in growth box (right) 
Table 1. The evolutionary cycle of the species Cydalima perspectalis Walk. in 2019 in Craiova area

\begin{tabular}{|c|c|c|c|c|}
\hline Development stages & \multicolumn{2}{|c|}{ Laboratory } & \multicolumn{2}{|c|}{ Field - 'Al. Buia’ Botanical Garden } \\
\hline \multicolumn{5}{|c|}{ Winter generation } \\
\hline Larval stage: & 04.03 & 01.04 & 08.03 & 27.04 \\
\hline minimum development period & \multicolumn{2}{|c|}{24 days } & \multicolumn{2}{|c|}{41 days } \\
\hline Pupae stage: first appearance & 28.03 & 15.04 & 18.04 & 10.05 \\
\hline \multirow[t]{2}{*}{ Adult stage: first appearance } & \multicolumn{2}{|c|}{10 days } & \multicolumn{2}{|c|}{15 days } \\
\hline & 07.04 & 25.04 & 03.05 & 29.05 \\
\hline \multicolumn{5}{|c|}{ The first generation } \\
\hline Egg stage: & 10.04 & 27.04 & 07.05 & 05.06 \\
\hline incubation period & \multicolumn{2}{|c|}{6 days } & \multicolumn{2}{|c|}{7 days } \\
\hline Larval stage: & 16.04 & 20.05 & 14.05 & 25.06 \\
\hline development period & \multicolumn{2}{|c|}{29 days } & \multicolumn{2}{|c|}{36 days } \\
\hline Pupae stage: & 15.05 & 30.05 & 19.06 & 07.07 \\
\hline development period & \multicolumn{2}{|c|}{10 days } & \multicolumn{2}{|c|}{12 days } \\
\hline Adult stage: & 25.05 & 12.06 & 01.07 & 26.07 \\
\hline \multicolumn{5}{|c|}{ The second generation } \\
\hline Egg stage: & 27.05 & 17.06 & 03.07 & 28.07 \\
\hline incubation period & \multicolumn{2}{|c|}{5 days } & \multicolumn{2}{|c|}{6 days } \\
\hline Larval stage: & 01.06 & 02.07 & 09.07 & 19.08 \\
\hline development period & \multicolumn{2}{|c|}{28 days } & \multicolumn{2}{|c|}{32 days } \\
\hline Pupae stage: & 28.06 & 11.07 & 10.08 & 30.08 \\
\hline development period & \multicolumn{2}{|c|}{9 days } & \multicolumn{2}{|c|}{10 days } \\
\hline Adult stage: & 07.07 & 23.07 & 20.08 & 12.09 \\
\hline \multicolumn{5}{|c|}{ The third generation } \\
\hline Egg stage: & 09.07 & 27.07 & 22.08 & 16.09 \\
\hline incubation period & \multicolumn{2}{|c|}{5 days } & \multicolumn{2}{|c|}{6 days } \\
\hline Larval stage: & 14.07 & 17.08 & 28.08 & 10.10 \\
\hline development period & & & & \\
\hline Pupae stage: & 12.08 & 29.08 & 03.10 & 21.10 \\
\hline development period & & & & \\
\hline Adult stage: & 20.08 & 10.09 & 15.10 & *** \\
\hline & & neration & & \\
\hline Egg stage: & 22.08 & 12.09 & 18.10 & $* * *$ \\
\hline incubation period & & & & \\
\hline Larval stage: & 27.08 & 30.09 & 25.10 & wintering \\
\hline development period & & & & \\
\hline Pupae stage: & 24.09 & 10.10 & $* * *$ & *** \\
\hline development period & & & & \\
\hline Adult stage: & 04.10 & 27.10 & $* * *$ & $* * *$ \\
\hline & & eration & & \\
\hline Egg stage: & 07.10 & 30.10 & $* * *$ & $* * *$ \\
\hline incubation period & & & & \\
\hline Larval stage: & 13.10 & vintering & $* * *$ & $* * *$ \\
\hline development period & & & & \\
\hline
\end{tabular}




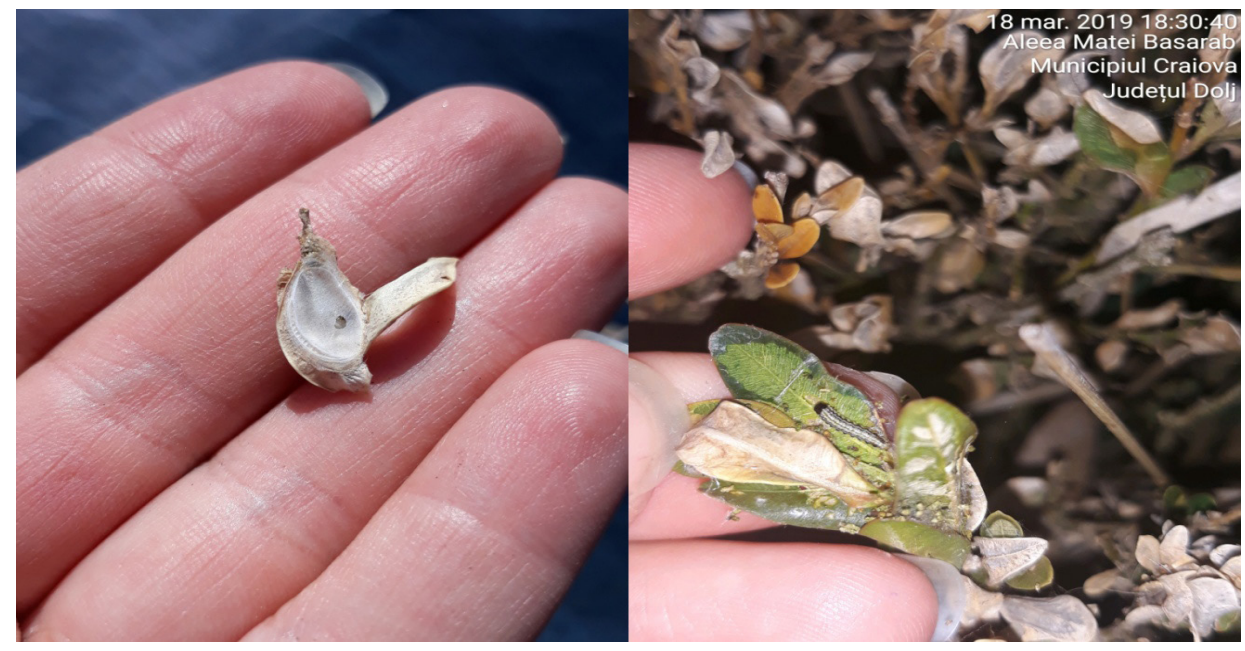

Figure 2. Cocoon hibernating larvae in the field (left) and larvae in the field (right)

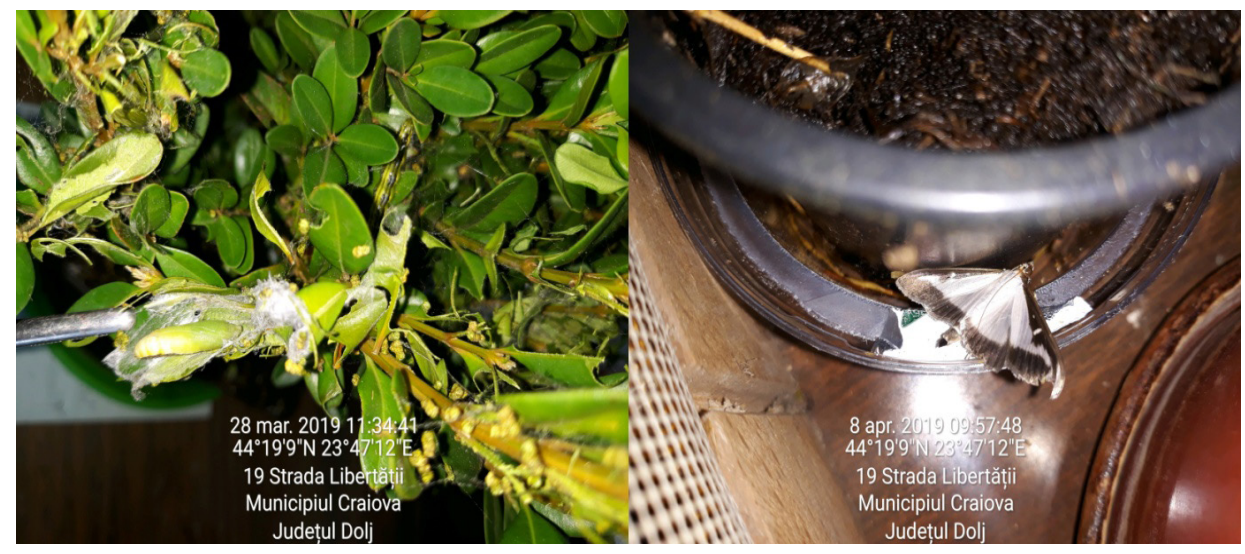

Figure 3. First pupae in the laboratory (left); First adult of the population raised in the laboratory (right)

was 29 days. In the field the preoviposition period was 4 days, and the incubation period was 7 days, the larvae of the first generation appeared on May 14 and had a period of development of 36 days. The period of the pupae stage in the laboratory was 10 days, the first adults being observed on May 25. The minimum development period of the first generation of The Box Tree Moth was 45 days. In the field, the first pupae were reported on June 19 and the pupation period was 12 days. The first adults appear on first of July. The period of the evolutionary cycle of the first generation is 55 days.

The second generation appeared on May 27, the incubation period being one day shorter than the first generation. The evolution period of the larvae is 28 days, and the pupation period is 9 days. The first adults were observed on July 7 . The development period for the second generation is 42 days. In the field the second generation appeared at the beginning of July, period of development of larvae instars was 32 days, the pupae stage was 12 days, and the period of the evolutionary cycle of this generation is 48 days, 7 days shorter than the first generation.

In the laboratory, the third generation laid the eggs on July 9 , the first larvae started their activity on July 15, the larval development was 28 days, and the pupae stage was 8 days at a temperature of $26^{\circ} \mathrm{C}$, the first adults being observed on August 20 , the evolutionary cycle for the third generation in the laboratory was 42 days. In the field the third generation was observed on August 22, the larval development period was 36 days. During the research in the field we noticed that there were larvae that entered to diapause in the $4^{\text {th }}$ instar, others continuing their development. The first pupae were observed in the first decade of 


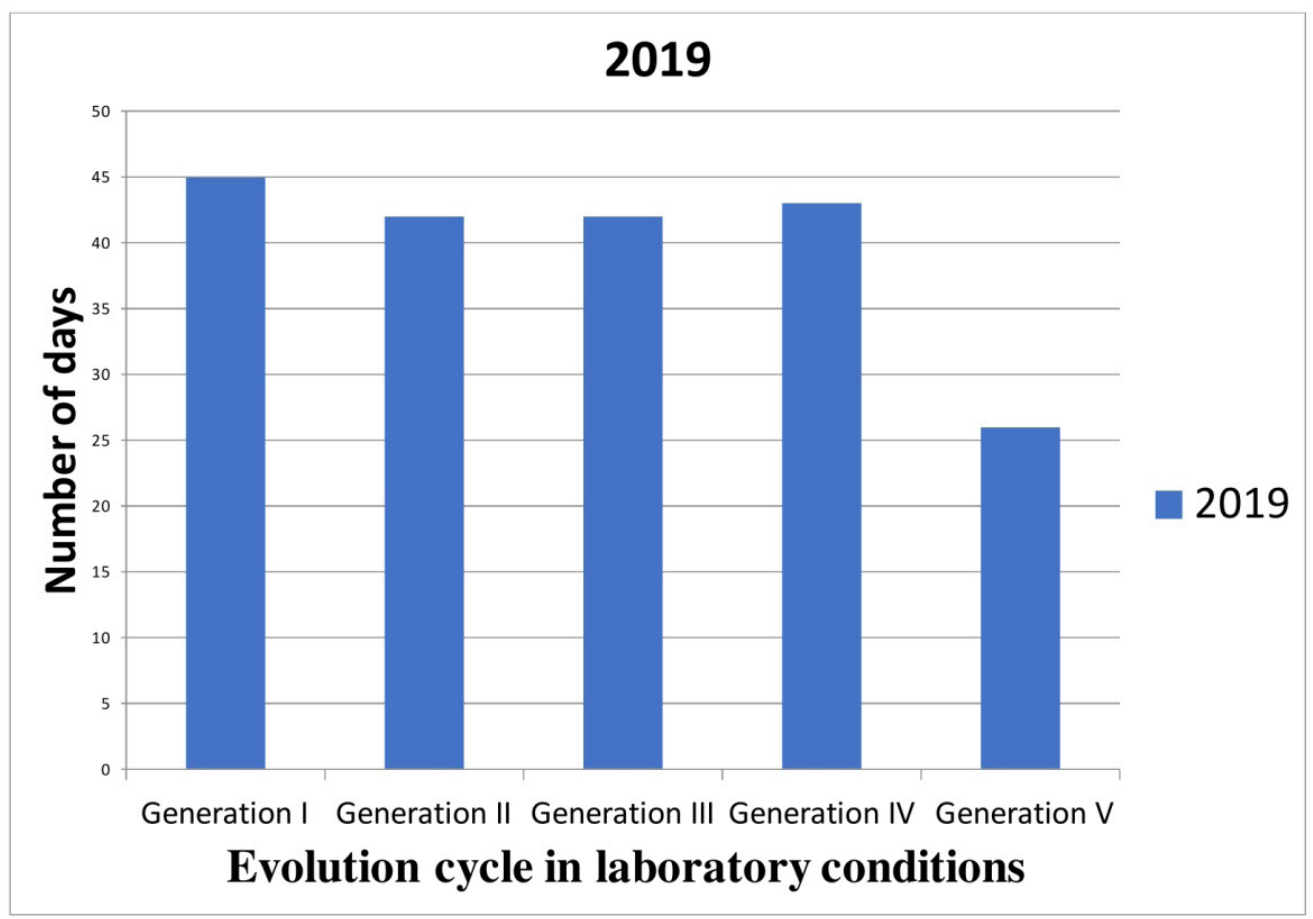

Figure 4. The evolutionary cycle developed in the laboratory / the period of the evolution of each generation (days)

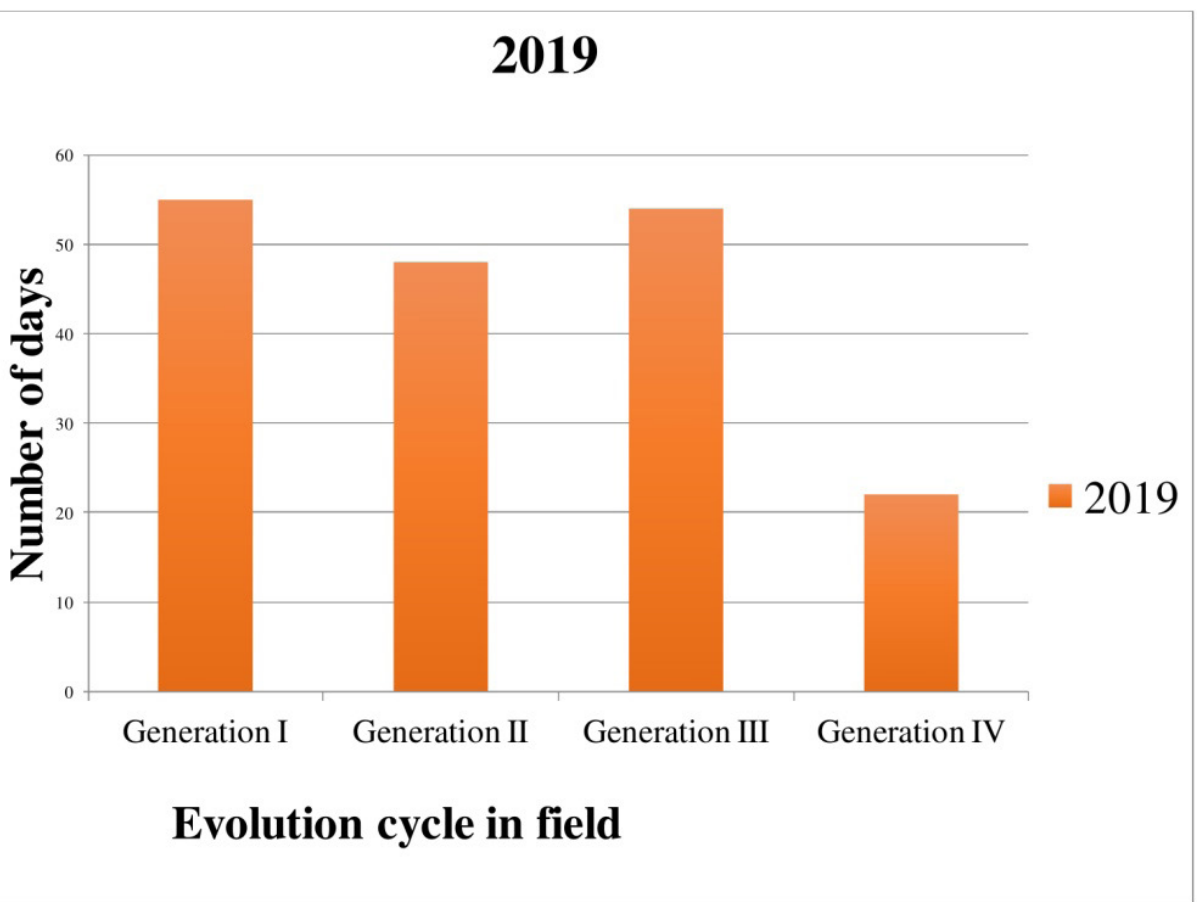

Figure 5. The evolutionary cycle of the species Cydalima perspectalis Walker developed in the field in 2019 
October, and the pupae stage was 12 days, the first adults were observed on October 15, and the evolutionary cycle of the third generation totaled 54 days.

The fourth generation in the laboratory appeared on August 22, the larval development was 28 days, and the pupae stage was 10 days. The first adults appeared on October 4, the preoviposition period was 3 days, and the incubation period was 6 days. The duration of the complete development of the fourth generation in the laboratory was 43 days. In the field the fourth generation is incomplete, the eggs were observed on October 18, and the first larvae on October 25, after a short period of feeding the larvae entered to hiemal diapause, at this point the larvae were in second and $3^{\text {rd }}$ instar.

The first eggs of the fifth generation appeared on October 7, and the first larvae appeared on October 13 , most of the larvae overwinter in $4^{\text {th }}$ instar. In laboratory conditions this species has developed 4 complete generations, and the $5^{\text {th }}$ generation is partial, the larvae of this generation overwinter in $4^{\text {th }}$ instar of development. (Fig. 4).

Following the observations made in the field, it was found that this species has developed 3 complete generations, and the $4^{\text {th }}$ generation is partial (Fig. 5).

The prolonged period of development of hibernating larvae was caused by low temperatures and the amount of precipitation, which slowed down and affected their growth and development. The hibernating generation in the laboratory totaled 34 days, and the field generation 56 days. The number of days of the generations developed in 2019 for the laboratory population is 272 days, and for the field population 286 days.

Comparing these data it is observed that the population grown in the laboratory is 14 days shorter than in the field, but the number of generations is different, in the laboratory the fourth generation was complete, thus giving birth to a fifth generation, and in the field the fourth generation was incomplete. The difference of one generation for the population raised in the laboratory conditions resulted from the climatic conditions, food and light conditions and all these factors producing an environment conducive to a prolonged evolutionary cycle.

\section{Conclusions}

Under laboratory conditions Cydalima perspectalis Walker has developed four complete generations, and the fifth generation was partial. In the field this pest has developed three complete generations, and the fourth is partial.

The number of days of the generations developed in 2019 for the laboratory population is 272 while for the field population is 286 days. The development period for the hibernating generation was 24 days in the laboratory at a temperature of $23^{\circ} \mathrm{C}$, and in the field it was 41 days at an average temperature between $11.0^{\circ} \mathrm{C}-11.9^{\circ} \mathrm{C}$ for March and April. The average period of larval development was between 28-29 days for the generations in the laboratory, respectively 32-36 for the generations that evolved in the field. Like the other stages of development, the pupation stage is also influenced by temperature, so the pupation period for the laboratory population varied between eight days (at a temperature of $26^{\circ} \mathrm{C}$ ) and ten days (at a temperature between $23^{\circ} \mathrm{C}-24^{\circ} \mathrm{C}$ ). In the field, the period of population depending on the generation varied between 15-10 days. The preovipsition period lasted between 2-4 days. Depending on the generation, the incubation varies between 5-6 days for the laboratory population and 6-7 days for the field population.

The difference of one generation for the population raised in the laboratory conditons resulted from the climatic conditions, food and light conditions, all these factors producing an environment conducive to a prolonged evolutionary cycle.

\section{Refrences}

1. Bella S (2013). The Box Tree Moth Cydalima perspectalis (Walker, 1859) Continues to spread in southern Europe: New records for Italy (Lepidoptera Pyraloidea Crambidae), REDIA, XCVI: 51-55.

2. Billen W (2007). Diaphania perspectalis (Lepidoptera: Pyralidae) - a new moth in Europe. Mitt der Entom Gesell Basel ,57: 135-137.

3. Brua C (2013). La pyrale du buis, Cydalima perspectalis (Walker, 1859), espece exotique envahissante, caracteristiques de sa dynamique d'expansion en France et en europe, des degats occasionnes sur les buis (buxus spp) et des strategies de lutte, AFPP - 3e conférence sur l'entretien des espaces verts, jardins, gazons, forêts, zones aquatiques et autres zones non agricoles Toulouse.

4. Brua C (2014). La pyrale du buis. Le point sur cette espèce envahissante. Phytoma: la santé des végétaux, 675: 16-22. 
5. Bunescu H, Florian T (2016), The Box Tree Moth, Cydalima perspectalis Walker (Lepidoptera: Crambidae: Spilomelinae) a New Invasive Species in Cluj Area (Romania), Bulletin UASVM, Faculty of Agriculture, ClujNapoca, Romania, 73(1): 62-65.

6. Cheng SP (2005). Studies on the box tree caterpillar, Diaphania perspectalis (Walker). Anhui Agri. Sci. Bull., 11: 107-108.

7. Don I, Don CI, Sasu LR, Vidrean D, Brad M (2016), Insect Pests On The Trees And Shrubs From The Macea Botaical Garden, Studia Universitatis "Vasile Goldiș" Arad, Seria Stiințe Inginerești și Agro-Turism, 11(2): 23-28.

8. Feldtrauer JF, Feldtrauer JJ, Brua C (2009). Premiers signalements en France de la Pyrale du Buis Diaphania perspectalis (Walker, 1859), espèce exotique envahissante s'attaquant aux Buis (Lepidoptera, Crambidae). Bulletin de la Société Entomolologique de Mulhouse, 65(4): 55-58.

9. Fora CG, Poșta DS (2015). Cydalima perspectalis Walk. (Lepidoptera: Crambidae), a dangerous pest of Buxus sempervirens in Timis County, Romania, Journal of Horticulture, Forestry and Biotechnology, USAMVB Timişoara, 19(3): 26-32.

10. Gugea I, Vîrteiu AM (2017). Remains Cydalima perspectalis (Lepidoptera: Crambidae) an invasive species dangerous for landscaping in western Romania?, Research Journal of Agricultural Science, 49 (4 ): 135-141.

11. Hizal E, Kose M, Yesil C, Kaynar D (2012). The new pest Cydalima perspectalis (Walker, 1859) (Lepidoptera:Crambidae) în Turkey, Journal of Animal And Veterinary Advances, 11(3): 400-403.

12. Iamandei M (2010). Diaphania perspectalis (Walker, 1859) (Lepidoptera: Crambidae) a new pest of Buxus spp. in Romania Lucrări ştiinţifice USAMVB, Seria B, 54: 787793.

13. Inoue $H$ (1982). Pyralidae. In: Moths of Japan 1, 2. In Inoue H, Sugi S, Kuroko H, Moriuti S, Kawabe A, Kodansha eds, Tokyo, 1: 307-404; 223-254; 2: 36-48; 228; 296-314.

14. Katona G, Ronkay L, Szabóky C, Bálint Z (2016). New data to the knowledge of the Lepidoptera Fauna of the SălajRegion, Transylvania, Romania (Arthropoda: Insecta), Studia Universitatis "Vasile Goldiș", Seria Științele Vieții, 26(4): 411- 414.

15. Korycinska A, Eyre D (2009). Box tree caterpillar Diaphania perspectalis, The Food and Environment Research Agency FERA, Plant pest factsheet, (https:// planthealthportal. defra.gov.uk/assets/factsheets/ boxTreeCaterpillar2011.pdf.

16. Kawazu K, Honda H, Nakamura S, Adati T (2007). Identification of sex pheromone components of the box tree pyralid, Glyphodes perspectalis. Journal of Chemical Ecology, 33(10): 1978-1985.

17. Leuthardt FLG, Billen W, Baur B (2010). Spread of the box-tree pyralid Diaphania perspectalis (Lepidoptera: Pyralidae) in the region of Basel - a pest species new for Switzerland. Entomo Helvetica, 3: 51- 57.

18. Leuthardt FLG, Baur B (2013). Oviposition preference and larval development of the invasive moth Cydalima perspectalis on five European box-tree varieties. Journal of Applied Entomology, 137: 437-444.
19. Mally R, Nuss M (2010). Phylogeny and nomenclature of the box tree moth, Cydalima perspectalis (Walker, 1859) comb. n., which was recently introduced into Europe (Lepidoptera: Pyraloidea: Crambidae: Spilomelinae). European Journal of Entomology, 107: 393-400.

20. Maruyama T, Shinkaji N (1987). Studies on the life cycle of the box-tree pyralid, Glyphodes perspectalis (Walker) (Lepidoptera: Pyralidae) I. Seasonal adult emergence and developmental velocity. Japanese Journal of Applied Entomology and Zoology, 31: 226-232.

21. Maruyama T, Shinkaji N (1991). The life cycle of the boxtree pyralid, Glyphodes perspectalis (Walker) (Lepidoptera: Pyralidae) II. Developmental characteristics of larvae. Japanese Journal of Applied Entomology and Zoology, 35: 221-230.

22. Maruyama T, Shinkaji N (1993). Life cycle of the box-tree pyralid, Glyphodes perspectalis (Walker) (Lepidoptera: Pyralidae) III. Photoperiodic induction of larval dia-pause. Japanese Journal of Applied Entomology and Zoology, 37: 45-51.

23. Matošević D (2013). Box Tree Moth (Cydalima perspectalis, Lepidoptera; Crambidae), New Invasive Insect Pest in Croatia. South-East Eur For., 4(2): 89-94.

24. Mitchell A (2009). Box tree moth Diaphania perspectalis (Walk.) - a new pyralid moth to Britain and Ireland. Atropos 36: 17-18.

25. Mitrea I, Stan R (2018). The New Pest Cydalima Perspectalis ( Walker, 1859) (Lepidoptera: Crambidae) In Area Of Central Oltenia. Annals Of The University Of Craiova, Vol. XXIII(LIX): 411-418.

26. Muus TST, Haaften Ejv, Deventer LJv (2009). The box-tree pyralid Palpita perspectalis (Walker) in The Netherlands (Lepidoptera: Crambidae). Entomologische Berichten, 69(2): 66-67.

27. Nacambo S, Leuthardt FLG, Wan H, Li H, Haye T, Baur B, Weiss RM, Kenis M (2014). Development characteristics of the box-tree moth Cydalima perspectalis and its potential distribution in Europe, J. Appl. Entomol. 138 :14-26.

28. Oltean I, Hulujan I, Varga M, Tötös Ş, Florian T (2017). Cydalima Perspectalis Walker (Lepidoptera, Crambidae) a New Dangerous Pest Report on Buxus Sempervirens in Cluj Area, Bulletin USAMV series Agriculture 74(1): 26-36.

29. Ostojić I, Zovko M, Petrović D, Elez D (2015). New records of box tree moth Cydalima perspectalis (Walker, 1859) in Bosnia and Herzegovina. Radovi Poljoprivrednoprehrambenog fakulteta, Univerziteta u Sarajevu (Works of the Faculty of Agricultural and Food Sciences, University of Sarajevo), 60(65): 139-143.

30. Park IK (2008). Ecological characteristic of Glyphodes perspectalis. Korean journal of applied entomology, 47(3): 299-301.

31. Sáfián S, Horváth B (2011). Box tree moth - Cydalima perspectalis (Walker, 1859), new member in lepidoptera fauna of Hungary (Lepidoptera: Crambidae). Natura Somogyiensis, 19: 245-246.

32. Salisbury A, Korycinska A, Halstead AJ (2012). The First Occurrence Of Larvae of The Box Tree Moth, Cydalima Perspectalis (Lepidoptera: Crambidae) In Private Gardens In The Uk, Br. J. Ent. Nat. Hist., 25: 1-6. 
33. Santi F, Radeghieri F, Sigurtà GI, Maini S (2015). Sex pheromone traps for detection of the invasive box tree moth in Italy, Bulletin of Insectology 68 (1): 158-160,

34. Seljak G (2012): Six new alien phytophagous insect species recorded in Slovenia in (2011). Acta Entomologica Slovenica, 20(1) :31-44.

35. She DS, Feng FJ (2006). Bionomics and Control of Diaphania perspectalis (Walker). J. Zhejiang Forest. Sci. Tech., 26: 47-51.

36. Skolka M, R. Zaharia (2014). Cydalima perspectalis (Lepidoptera: Crambidae) - new invasive species in Constanța, International Zoological Congress of "Grigore Antipa" Museum, Book of Abstracts, Bucharest, Ed. Medialux, București, 181-182.

37. Székely L, Dincă V, Mihai C (2011). Cydalima perspectalis (Walker, 1859), a new species for the Romanian fauna (Lepidoptera: Crambidae: Spilomelinae), Bul.inf. Entomol., 22: 73-78.

38. Van Der Straten MJ, Muus TST (2010). The box-tree pyralid, Glyphodes perspectalis (Lepidoptera: Crambidae), an invasive alien moth ruining box-trees. Proceedings of the Netherlands Entomological Society Meeting, 21: 107111.

39. Wan H, Haye T, Kenis M, Nacambo S, Xu H, Zhang F, Li $\mathrm{H}$ (2014). Biology and natural enemies of Cydalima perspectalis in Asia: Is there biological control potential in Europe?, J. Appl. Entomol., doi: 10.1111/jen.12132.

40. Wang YM (2008). The biological character and control of a new pest (Diaphania perspectalis) on Murraya paniculata. J. Fujian Forest. Sci. Tech., 35: 161-164.

41. Xiao HJ, Xin HQ Zhu XF, Xue FS (2011). Photoperiod and temperature response of diapause induction in Diaphania perspectalis (Lepidoptera: Crambidae). Chin. Journal of. Appl. Entomol., 48: 116-120.

42. Zhang L, Li ZH, Zhen XH, Chen M (2007). Biological characteristics and control of box tree caterpillar, Diaphania perspectalis (Walker). Shandong Agric. Sci., 2: 77-79.

43. Zhou W, Xia CY, Sun XQ, Zhu B, Liu XP, Liu ZC, Wang Y (2005). Studies on the biological characteristics and control of Diaphania perspectalis Walker. J. Shanghai Jiaotong Univ. Agric. Sci., 23: 52-56. 